\title{
CARDIOVASCULAR AND RENAL ADJUSTMENTS TO A HYPOTENSIVE AGENT
}

\author{
(l-HYDRAZINOPHTHALAZINE: CIBA BA-5968: APRESOLINE) ${ }^{1,2}$
}

\author{
By ERNEST L. WILKINSON, ${ }^{8}$ HEIKKI BACKMAN, ${ }^{3}$ AND HANS H. HECHT \\ (From the Department of Medicine, University of Utah College of Medicine, \\ Salt Lake City, Utah)
}

(Submitted for publication May 16, 1952; accepted July 30, 1952)

Since the work of Goldblatt, Lynch, Hanzal, and Summerville which related renal ischemia causally to hypertension (1), it has seemed logical to use renal vasodilators in the treatment of the syndrome. Yet the pyrogens are the only substances which heretofore have been demonstrated to increase consistently renal blood flow and these have not been found suitable for therapeutic use $(2,3)$. Chemical or hormonal compounds proposed as anti-hypertensive agents either exert a negligible effect on the renal circulation or reduce renal blood flow while lowering arterial pressure. These include the adrenergic blocking agent dibenamine $(4,5)$, the benzodioxanes $(6)$, the ergot alkaloids (7), and the imidazolines $(6,8)$. Xanthine derivatives, of which aminophylline may be considered the prototype, induce renal hyperemia only in congestive cardiac failure $(9,10)$. The commonly used peripheral vasodilators-nicotinic acid, histamine, and the nitrites-similarly fail to augment renal blood $(3,11)$.

l-Hydrazinophthalazine (Ciba BA-5968 or Apresoline) is the basic chemical compound and one of several substituted compounds which have in common the properties of $(a)$ increasing renal blood flow and $(b)$ reducing arterial pressure in both animals and man (12-16).

It has been shown that this drug antagonizes the pressor action of epinephrine and to a lesser extent that of nor-epinephrine $(14,17-20)$. It abolishes the pressor effect brought about by centripetal vagus stimulation and thought due to serotonin (21), and it has an inhibitory effect against

1 This project was supported (in part) by a grant from the National Heart Institute, U. S. Public Health Service, and by the Ciba Pharmaceutical Company.

2 Presented (in part) at the 5th Annual Meeting of the Western Society for Clinical Research, January 26, 1952, Carmel, California.

${ }^{3}$ Fellow in Medicine. the pressor action of angiotonin and possibly other factors causally related to hypertension (22-24). It modifies the pressor response to the cold pressor test and the overshoot following the Valsalva maneuver (24). It causes increased coronary blood flow in the canine heart lung preparation (25). The site of action is unknown but it has been suggested that this drug reduces the outflow of sympathetic vasopressor impulses by central action (26).

It was the purpose of this study to measure and to evaluate certain cardiovascular and renal adjustments induced by this compound in normal and in hypertensive subjects.

\section{METHOD}

A total of 27 patients were studied. All were given $l$-hydrazinophthalazine in rapid single intravenous doses of $0.25-0.50 \mathrm{mgm} . / \mathrm{Kg}$./body weight. Basal determinations of blood pressure and pulse were made before administration of the drug and these were repeated every $30 \mathrm{sec}-$ onds to five minutes for one to two hours thereafter, depending upon the rate of change.

Renal plasma flow ( $\mathrm{C}_{\mathbf{P A}}$ ) and glomerular filtration rate $\left(C_{1 N}\right)$ were simultaneously measured in 16 patients by the conventional clearance techniques (27).4 All values before administration of the drug represent the average of at least three successive urine collection periods of 12-20 minutes each. Following administration of the drug several additional successive collections of similar duration were made.

Cardiac catheterization was performed in four healthy normotensive, non-hospitalized subjects and in two patients with hypertensive heart disease. Cardiac output, vascular resistance and work load were determined during the basal state and at intervals following administration of $l$-hydrazinophthalazine up to two hours. Cardiac output was measured by the usual determination of oxygen consumption and $\mathrm{A}-\mathrm{V}$ oxygen difference.

4 For the determination of inulin, auto-oxidation of glucose was substituted for destruction of glucose by fermentation, according to the modification of J. M. Little ( J. Biol. Chem., 1949, 180, 747). 
Electrocardiograms were recorded serially in three normal subjects. In ten normal subjects skin temperatures were recorded simultaneously over six positions by means of an automatically recording potentiometer. Readings were made continuously in a constant temperature room at $22-33^{\circ}$ Centigrade in the post-absorptive state for several hours before and after intravenous or intraarterial injection of the compound.

\section{RESULTS}

\section{1) Renal function}

The renal plasma flow increased in 12 of 16 subjects, the average maximum increase being $38 \%$ (11-122\%) (Figure 1). Of the four patients

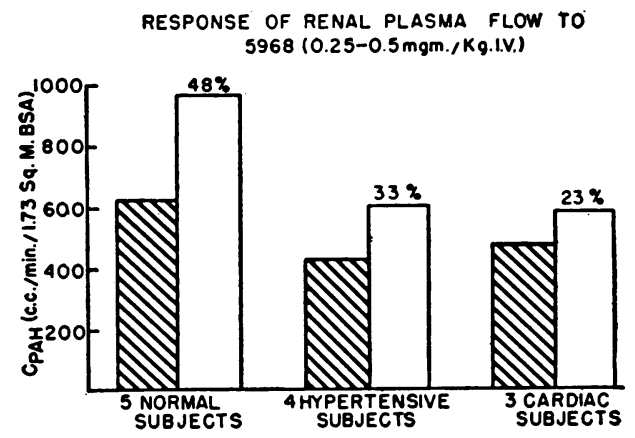

Fig. 1. Renal Plasma Flow Before (Shaded) and After Administration of Apresoline

The hypertensive group does not include the three patients with clinical shock.

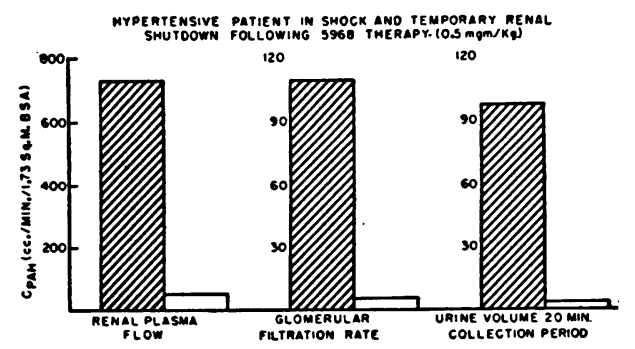

Fig. 2. Apparent Cessation of Renal Blood Flow During Period of Pronounced Hypotension Following the Administration of Apresoline in C. B., a 28-YearOld Male with Essential Hypertension

Two other patients responded similarly.

failing to demonstrate an increase in renal plasma flow, three had severe benign essential hypertension and manifested a pronounced and sustained fall in arterial pressure to shock levels in the recumbent position with consequent temporary but almost complete cessation of renal blood flow in two of the patients (Figure 2). The fourth patient had rheumatic heart disease with mitral stenosis and aortic insufficiency and was in incipient congestive cardiac failure. Of the 12 patients in whom the renal plasma flow increased, five were normotensive and the average maximum rise was $48 \%$ in this group. Four patients had essential hypertension with an average maximum

TABLE I

Renal plasma flow ( $\left.\mathrm{C}_{\mathrm{PAH}}\right)$, glomerular filtration $\left(\mathrm{C}_{\mathrm{In}_{\mathrm{n}}}\right)$, and filtration fraction $(F . F$.$) in 16$ subjects following the intravenous administration of Apresoline (Ciba-5968)

\begin{tabular}{|c|c|c|c|c|c|c|c|c|c|c|}
\hline \multirow{2}{*}{ Patient } & \multirow{2}{*}{ Age } & \multirow{2}{*}{ Diagnosis } & \multirow{2}{*}{$\begin{array}{c}\text { Dosage } \\
5968 \text { I.V., mgm./Kg. }\end{array}$} & \multicolumn{3}{|c|}{ Before } & \multicolumn{3}{|c|}{ After } & \multirow[b]{2}{*}{$\underset{\text { CPAB }_{\text {Max. }}^{*}}{\text { Mat }}$} \\
\hline & & & & $\mathrm{C}_{\mathrm{PAH}}{ }^{*}$ & $C_{I^{*}}$ & F.F. & $\mathrm{C}_{\mathrm{PAB}(1)^{*}}$ & $C_{I_{n}}{ }^{*}$ & F.F. & \\
\hline $\begin{array}{l}\text { 1. C. B. } \\
\text { 2. O. O. } \\
\text { 3. J. W. } \\
\text { 4. W. C. } \\
\text { 5. J. B. } \\
\text { 6. M. B. } \\
\text { 7. D. L. } \\
\text { 8. W. J. } \\
\text { 9. M. S. } \\
\text { 10. A. P. } \\
\text { 11. C. B. } \\
\text { 12. E. C. } \\
\text { 13. S. H. } \\
\text { 14. A. K. } \\
\text { 15. L. T. } \\
\text { 16. P. V. V. }\end{array}$ & $\begin{array}{l}21 \\
39 \\
30 \\
30 \\
32 \\
45 \\
31 \\
63 \\
57 \\
59 \\
28 \\
62 \\
46 \\
23 \\
27 \\
59\end{array}$ & $\begin{array}{l}\text { Normal } \\
\text { Normal } \\
\text { Normal } \\
\text { Normal } \\
\text { Normal } \\
\text { Ess. hypertension } \\
\text { Coarctation of aorta } \\
\text { Ess. hypertension } \\
\text { Ess. hypertension } \\
\text { Ess. hypertension } \\
\text { Ess. hypertension } \\
\text { Ess. hypertension } \\
\text { Hyp. heart dis. } \\
\text { Ess. hypertension } \\
\text { RHD with M.S. } \\
\text { RHD with M.S. and A.I. } \\
\text { Chr. pulm. dis. } \\
\text { Cor. pulmonale }\end{array}$ & 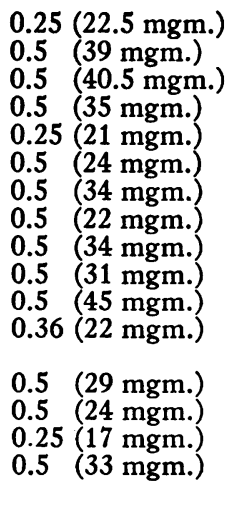 & $\begin{array}{l}754 \\
669 \\
814 \\
566 \\
541 \\
532 \\
772 \\
246 \\
321 \\
252 \\
733 \\
320 \\
\\
380 \\
538 \\
536 \\
356\end{array}$ & $\begin{array}{r}117 \\
107 \\
156 \\
\\
92 \\
84 \\
131 \\
63 \\
53 \\
42 \\
110 \\
83 \\
\\
67 \\
97 \\
106 \\
116\end{array}$ & $\begin{array}{l}.16 \\
.16 \\
.19 \\
.17 \\
.16 \\
.17 \\
.25 \\
.16 \\
.17 \\
.15 \\
.26 \\
.18 \\
.18 \\
.20 \\
.32\end{array}$ & $\begin{array}{r}936 \\
1443 \\
985 \\
780 \\
696 \\
705 \\
860 \\
303 \\
458 \\
342 \\
51 \dagger \\
25 \dagger \\
\\
202 \dagger \\
887 \\
451 \\
418\end{array}$ & $\begin{array}{r}105 \\
160 \\
152 \\
\\
110 \\
86 \\
110 \\
54 \\
50 \\
47 \\
5 \\
3 \\
\\
24 \\
96 \\
93 \\
111\end{array}$ & $\begin{array}{l}.11 \\
.11 \\
.15 \\
.16 \\
.12 \\
.13 \\
.18 \\
.11 \\
.14 \\
.10\end{array}$ & $\begin{array}{l}+24 \% \\
+116 \% \\
+21 \% \\
+38 \% \\
+29 \% \\
+33 \% \\
+11 \% \\
+23 \% \\
+43 \% \\
+34 \% \\
-93 \% \\
-92 \% \\
+47 \% \\
+65 \% \\
+16 \%\end{array}$ \\
\hline
\end{tabular}

* All clearances expressed as cc./min./1.73 Sq.M. BSA.

$\dagger$ Patient in shock. 


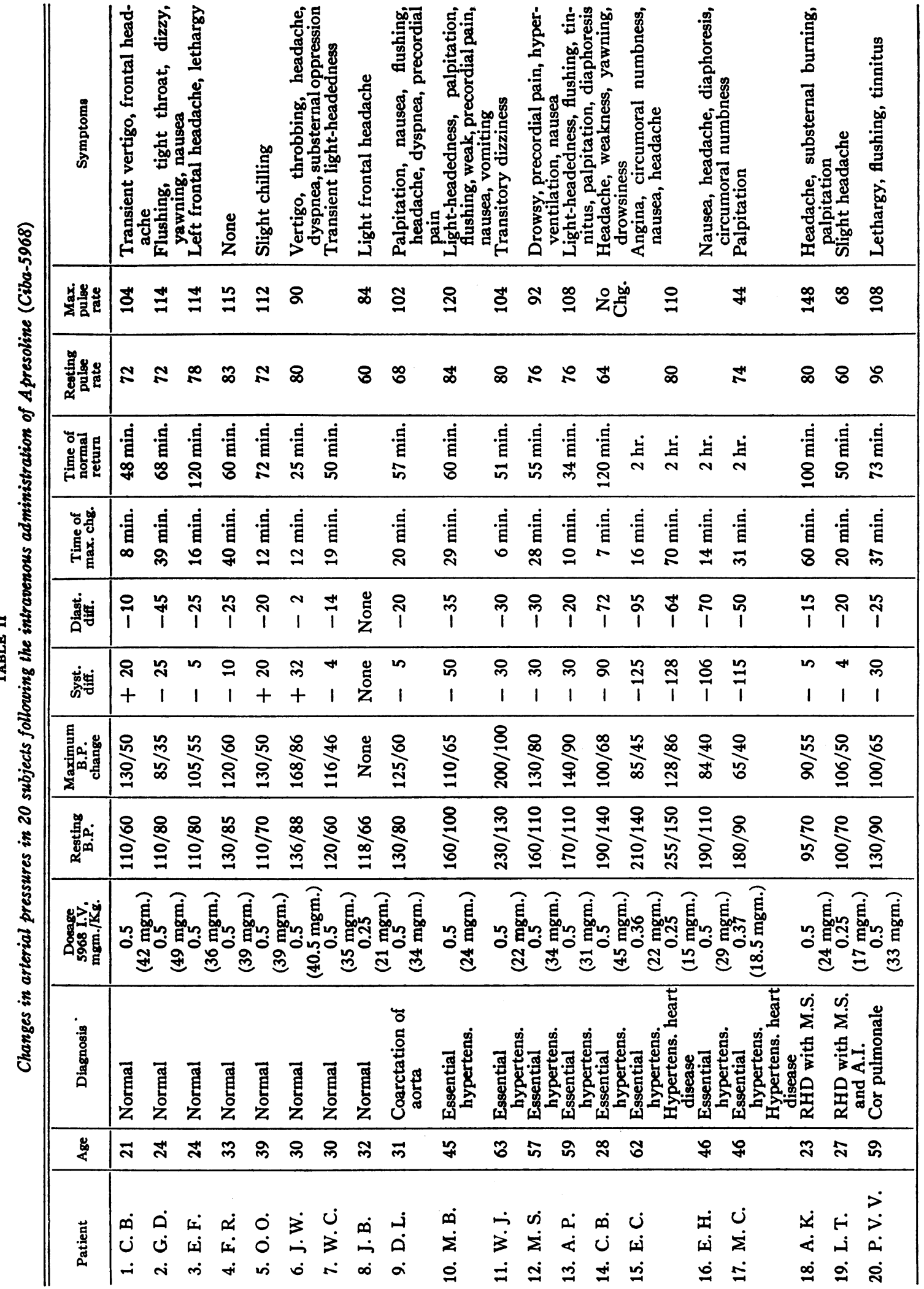


rise of $33 \%$. The lowest maximum rise was in patient No. 7 with coarctation of the aorta. The changes in renal plasma flow are statistically significant $(\mathrm{t}=4.08, \mathrm{p}<0.01)$.

No consistent change in glomerular filtration rate occurred; it follows, therefore, that the filtration fraction was decreased (Table I). A diuretic action was a frequent but inconstant effect.

\section{2) Arterial pressure}

In eight normotensive subjects no consistent change in the level of systolic arterial pressure was noted while in the hypertensive group systolic pressures fell regularly following the administration of this compound (Table II). The fall in pressure in this group averaged $66 \mathrm{~mm} . \mathrm{Hg}$ and was statistically highly significant $(t=3.55, \mathrm{p}<$ 0.01 ).

A diastolic blood pressure fall was a constant finding and in eight normotensive subjects diastolic arterial pressures decreased an average of $18 \mathrm{~mm}$. $\mathrm{Hg}(\mathrm{t}=3.18, \mathrm{p}<0.01)$. The average maximum diastolic fall in the hypertensive group of patients was $50 \mathrm{~mm}$. $\mathrm{Hg}$ (range 15-95). The maximum diastolic fall in both groups occurred within an average of 20 minutes and rarely returned to the pre-drug level within an hour, often not before two hours or longer. If the three patients are excluded who responded to the drug with sharp diminution of renal blood flow to shock levels, the average fall in diastolic pressure in the remaining hypertensive patients was $30 \mathrm{~mm}$. $\mathrm{Hg}$, excluding one patient in whom renal studies were not available but who demonstrated a severe reduction in arterial pressure from $180 / 90$ to $80 / 46$. Whenever measured, no fall in pressure was noted in the pulmonary circulation (see below).

Tachycardia was an almost constant occurrence although occasionally excessive bradycardia was observed. Frequent minor side effects were noted. Of these, palpitation, transient light headedness, frontal headache, flushing of the head and neck, nausea and vomiting, and circumoral numbness were most common. These symptoms were accentuated in the upright position and orthostatic accentuation of the hypotension was usually present.

With the exception of the sinus tachycardia previously noted, there were no electrocardio- graphic abnormalities observed throughout serial recordings in three normal subjects.

\section{3) Skin temperature}

Skin temperature studies were performed in eight patients, only one of whom was subjected to other Apresoline studies. The intravenous injection of the drug to five patients at constant temperature of $22-33^{\circ} \mathrm{C}$. failed to increase the skin temperatures of the extremities. In one patient two separate intra-arterial injections of $0.10 \mathrm{mgm}$. (0.25 mgm./Kg.) were also ineffectual. In one patient with unilateral sympathectomy the temperature of the uninvolved extremity rose slowly to the level of the sympathectomized limb after a total of $20 \mathrm{mgm}$. ( $0.30 \mathrm{mgm} . / \mathrm{Kg}$.) had been injected into the femoral artery. In three other sub-
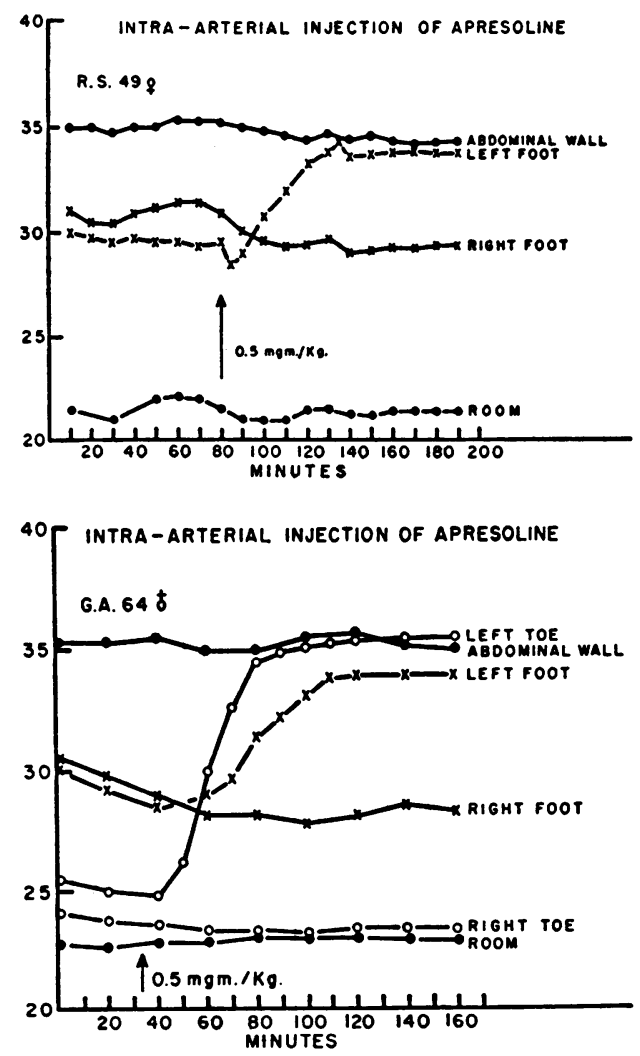

Figs. 3a and 3b. Intra-Arterial Injection of Apresoline into the Left Femoral Artery of Two Subjects, with High (a) and Low (b) Resting Temperature of THE LOWER EXTREMITY

All measurements were made through a seven-point automatic constant recording potentiometer with temperatures recorded every two minutes. Ordinate scale in ${ }^{\circ} \mathrm{C}$. 


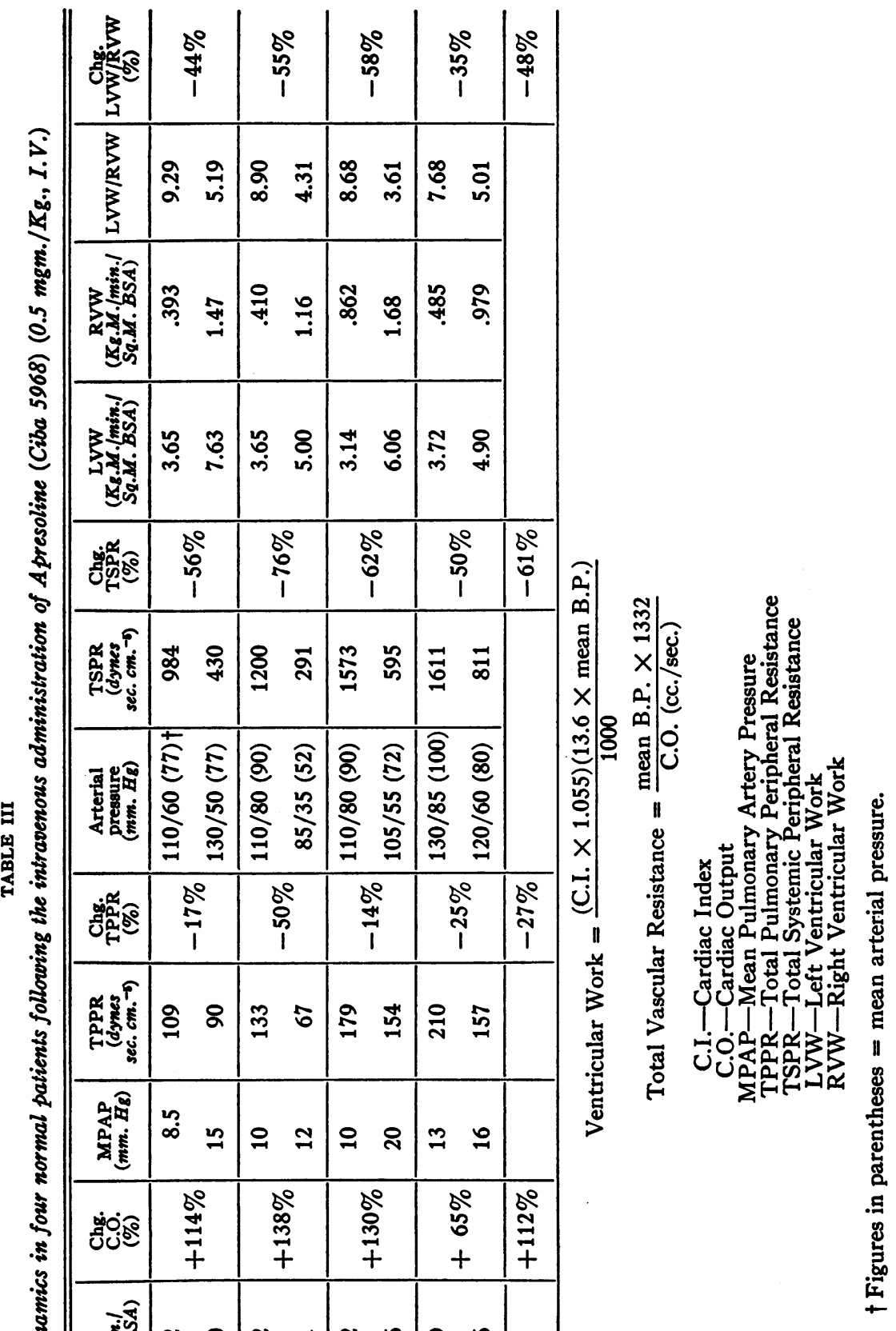


jects $0.5 \mathrm{mgm} . / \mathrm{Kg}$. of Apresoline injected into the femoral artery caused a prompt rise in the surface temperature of the extremity involved (Figure 3).

\section{4) Cardiac output}

In four healthy normotensive subjects the cardiac output was sharply increased by $l$-hydrazinophthalazine (Table III, Figure 4). The maximum increase in cardiac output in the four cases occurred in 15 to 45 minutes after the drug was administered and then slowly declined. Cardiac output rose an average of $110 \%$. The output increased disproportionately to the tachycardia so that the stroke volume increased an average of $66 \%$. The mean pulmonary artery pressure changed slightly from an average of $11 \mathrm{~mm}$. $\mathrm{Hg}$ to $16 \mathrm{~mm} . \mathrm{Hg}$. Because of the excessive rise in cardiac output the calculated total pulmonary resistance fell by an average of $27 \%$ when the appropriate formulae were employed. The total systemic resistance, on the other hand, decreased an average of $61 \%$ due to the fall in arterial pressure concomitant with a rise in output.

Because pulmonary artery pressures did not share in the peripheral vasodilatation the right ventricular work was disproportionately increased over the left ventricular work so that the ratio LVW/RVW was reduced by one-half.

In two patients with hypertensive heart disease, who had previously been in congestive failure, cardiac output increased only $17 \%(1.23 \mathrm{~L} . / \mathrm{min}$. and $21 \%(0.85 \mathrm{~L} . / \mathrm{min}$. $)$ respectively. In one patient pulmonary artery pressures rose from a mean of 21 to $51 \mathrm{~mm}$. Hg while the arterial pressure fell from a mean of 190 to $100 \mathrm{~mm}$. $\mathrm{Hg}$. In

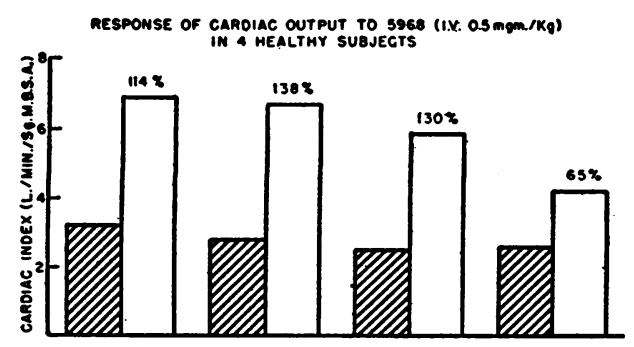

Fig. 4. A Sharp Increase in both Stroke Volume ANd Minute Output Occurred in Four Normotensive Subjects Immediately upon Injection of Apresoline aNd LASTed for Approximately One Hour the second patient pulmonary artery pressure remained essentially unchanged at $18 \mathrm{~mm}$. $\mathrm{Hg}$ while the systemic pressure fell from a mean of 120 to $57 \mathrm{~mm}$. Hg. The significance of these observations in subjects with a lowered cardiac reserve remains to be evaluated.

\section{DISCUSSION}

$l$-Hydrazinophthalazine lowers arterial diastolic pressure when administered intravenously and with equal dosage the fall in pressure is proportionately greater in hypertensive subjects than in normal individuals. Systolic pressure declined only in the hypertensive patients. Renal blood flow increased in all normal subjects but in contrast to the fall in pressure the increase was more striking in the normal than in patients with hypertension or heart disease. The difference between these groups was found to be statistically significant. These observations do not support the assumption that lowering of arterial pressure was mediated by an increase in renal blood flow. The two actions are apparently not interdependent.

The fall in arterial pressure was not caused by uniform vasodilatation. Pulmonary artery pressure did not fall and the intravenous injection of a hypotensive dose of Apresoline failed to cause a significant elevation in skin temperature when measurements were made over widely divergent areas. Its local vasodilating action could be demonstrated, however, by injecting large amounts of the drug intra-arterially. The fall in pressure is not the result of a lowered cardiac output in either normal or hypertensive subjects in whom adequate studies were available. It appears likely that selective vasodilatation, presumably of the splanchnic vessels, is responsible for the observed decrease in peripheral resistance.

The sharp increase in cardiac output and stroke volume in normal subjects together with the fall in pressure is of interest. The per cent increase in cardiac output exceeded the per cent increase in renal blood flow. Though measurements were not obtained simultaneously or in the same individuals, it does not appear likely that the results are random variations (Tables I, III). In the light of these observations a relative decrease in renal blood flow may be considered the renal pattern of this compound. That is, renal blood flow 
increases, though to a lesser extent than the systemic blood flow.

The cardiovascular adjustments, characterized by an excessive decrease in total arteriolar resistance, are reminiscent of those observed following the administration of epinephrine in subjects in whom the vasoexcitor components of epinephrine have been blocked by dibenamine and who demonstrate Dale's blood pressure reversal in the face of increased cardiac output (28). It is to be stressed that a fall in arterial pressure in the face of increased cardiac output must represent marked peripheral vascular relaxation and for this reason Apresoline is considered a strong but selective vasodilator with properties resembling the vasodilator component of epinephrine, or epinephrine itself as contrasted with nor-epinephrine.

\section{SUM MARY}

\section{1. l-Hydrazinophthalazine (Ciba BA-5968,} Apresoline) was administered to 27 subjects in single intravenous or intra-arterial doses of 0.25 to $0.5 \mathrm{mgm} . / \mathrm{Kg}$. body weight.

2. A fall in systolic pressure occurred in hypertensive subjects only. Diastolic arterial pressures fell in all but two instances.

3. Renal blood flow ( $\mathrm{C}_{\mathrm{PAB}}$ ) increased by an average of $40 \%$, total peripheral blood flow (cardiac output) by $110 \%$ in the normal, resulting in a relative decrease of the fraction of the total blood flow made available to the kidneys.

4. No significant changes in skin temperatures were noted following intravenous injections. Intra-arterially administered, Apresoline caused a prompt and sustained rise in temperature of the involved extremity.

5. The compound represents a potent selective vasodilator with cardiac stimulating properties.

\section{ACKNOWLEDGMENT}

The authors wish to acknowledge the indispensable help of Mrs. Louise Green and Mr. Filimon Ukradaya.

\section{REFERENCES}

1. Goldblatt, H., Lynch, J., Hanzal, R. F., and Summerville, W. W., Studies on experimental hypertension. I. The production of persistent elevation of systolic blood pressure by means of renal ischemia. J. Exper. Med., 1934, 59, 347.
2. Bradley, S. E., Chasis, H., Goldring, W., and Smith, $H$. W., Hemodynamic alterations in normotensive and hypertensive subjects during the pyrogenic reaction. J. Clin. Invest., 1945, 24, 749.

3. Chasis, H., Ranges, H. A., Goldring, W., and Smith, H. W., The control of renal blood flow and glomerular filtration in normal man. J. Clin. Invest., 1938, 17, 683.

4. Wang, C. Y., and Nickerson, M., Effect of dibenamine on renal function. Proc. Soc. Exper. Biol. \& Med., 1949, 70, 92.

5. Ogden, E., Influence of dibenamine on renal function of the dog. Federation Proc., 1948, 7, 87.

6. Nickerson, M., The pharmacology of the adrenergic blockade. J. Pharmacol. \& Exper. Therap., 1949, 95, Part II, 27.

7. Reubi, F. C., Influence de quelques vasodilateurs périphériques sur le flux sanguin rénal. Helvet. med. acta, 1949, 16, 297.

8. Personal observations.

9. Escher, D. J. W., Weston, R. E., Leiner, G., Leiter, L., and Goldat, S., The effect of aminophyllin on cardiac output and renal hemodynamics in man. Federation Proc., 1948, 7, 31.

10. Sinclair-Smith, B., Kattus, A. A., Genest, J., and Newman, E. V., The renal mechanism of electrolyte excretion and the metabolic balances of electrolytes and nitrogen in congestive cardiac failure; the effects of exercise, rest and aminophyllin. Bull. Johns Hopkins Hosp., 1949, 84, 369.

11. Reubi, F. C., and Futcher, P. H., The effects of histamine on renal function in hypertensive and normotensive subjects. J. Clin. Invest., 1949, 28, 440.

12. Reubi, F. C., Renal hyperemia induced in man by a new phthalazine derivative. Proc. Soc. Exper. Biol. \& Med., 1950, 73, 102.

13. Schmid, A., and Reubi, F. C., Hämodynamische Eigenschaften zweier neuer Phthalazinderivate. Helvet. med. acta, 1950, 17, 543.

14. Gross, F., Druey, J., and Meier, R., Eine neue Gruppe blutchrucksenkender Substanzen von besonderem wirkungscharakter. Experientia, 1950, 6, 19.

15. Schroeder, H. A., The effects of $l$-hydrazinophthalazine in hypertension. Circulation, 1952, 5, 28.

16. Schroeder, H. A., Effects on hypertension of sulfhydryl and hydrazine compounds. J. Clin. Invest., 1951, 30, 672.

17. Craver, B. N., Barrett, W., Cameron, A., and Yonkman, F. F., The activities of $l$-hydrazinophthalazine (BA-5968), a hypotensive agent. J. Am. Pharmaceutic. A. (Scient. Ed.), 1951, 40, 559.

18. Craver, B. N., and Yonkman, F. F., Some pharmacological properties of $l$-hydrazinophthalazine, a hypotensive agent. Federation Proc., 1950, 9, 265.

19. Freis, E. D., MacKay, J. C., and Oliver, W. F., The effect of "sympatholytic" drugs on the cardiovascular response of epinephrine in man. Circulation, 1951, 3, 254. 
20. Walker, H. A., Wilson, S., Atkins, E. C., Garrett, H. E., and Richardson, A. P., The effect of $l$-hydrazinophthalazine (C-5968) and related compounds on the cardiovascular system of dogs. J. Pharmacol. \& Exper. Therap., 1951, 101, 368.

21. Editorial: Hormonal cerebral vasopressor substances, J.A.M.A., 1951, 146, 1326.

22. Taylor, R. D., Page, I. H., and Corcoran, A. C., A hormonal neurogenic vasopressor mechanism. Arch. Int. Med., 1951, 88, 1.

23. Page, I. H., and McCubbin, J., Unpublished observations cited by Taylor, Page and Corcoran (22).

24. Freis, E. D., and Finnerty, F. A., Jr., Suppression of vasomotor reflexes in man following $l$-hydrazino- phthalazine. Proc. Soc. Exper. Biol. \& Med., 1950, $75,23$.

25. Barrett, W., Reitze, W., Plummer, A. J., and Yonkman, F. F., Coronary dilating action of $l$-hydrazinophthalazine (BA-5968) (Apresoline) in the canine heart lung preparation. Federation Proc., 1952, 11, 320.

26. Yonkman, F. F., Neurogenic hypertension; chemical approaches to its amelioration. J. Mich. Med. Soc., 1951, 50, 160.

27. Goldring, W., and Chasis, H., Hypertension and $\mathrm{Hy}-$ pertensive Disease. The Commonwealth Fund, New York, 1944 (Appendix D).

28. Personal observations. 